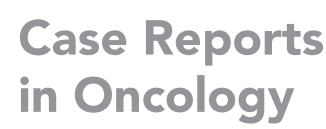

Case Reports

in Oncology

\title{
Successful Treatment of Combined Large Cell Neuroendocrine Carcinoma Harboring an EGFR Mutation with EGFR-TKIs plus Bevacizumab: A Case Report
}

\author{
Satoshi Muto ${ }^{a} \quad$ Yuki Ozaki $^{a} \quad$ Naoyuki Okabe ${ }^{a}$ Yuki Matsumura ${ }^{a}$ \\ Takeo Hasegawa $^{a}$ Yutaka Shio $^{a}$ Yuko Hashimoto $^{\mathrm{b}}$ Hiroyuki Suzuki ${ }^{\mathrm{a}}$ \\ aDepartment of Chest Surgery, Fukushima Medical University, Fukushima, Japan; \\ ${ }^{b}$ Department of Diagnostic Pathology, Fukushima Medical University, Fukushima, Japan
}

\author{
Keywords \\ Large cell neuroendocrine carcinoma - Epidermal growth factor receptor mutation - Tyrosine \\ kinase inhibitors · Bevacizumab
}

\begin{abstract}
Large cell neuroendocrine carcinoma (LCNEC) of the lung with epidermal growth factor receptor (EGFR) mutation is rare, and few cases have been treated with EGFR tyrosine kinase inhibitors (TKIs). We report the treatment of combined LCNEC with adenocarcinoma harboring an EGFR mutation with EGFR-TKIs and bevacizumab. Our patient was a 70-year-old asymptomatic woman who underwent surgical resection of the lung for combined LCNEC with adenocarcinoma harboring an activating EGFR mutation 11 months previously. Magnetic resonance imaging (MRI) and positron emission tomography revealed metastatic lesions in the brain and lung. The patient was diagnosed with recurrence of combined LCNEC with adenocarcinoma. The brain lesion was irradiated, followed by administration of afatinib. Eight months after irradiation, brain MRI revealed ringed enhancement and perilesional edema after radiotherapy without new metastatic lesions. We switched treatment to erlotinib and bevacizumab, resulting in maintenance of stable disease for 10 months. Overall, the disease was controlled for 18 months with EGFR-TKIs and bevacizumab. Combination treatment with EGFR-TKIs and bevacizumab could be a treatment option for LCNEC of the lung harboring EGFR mutations, especially with brain metastasis.




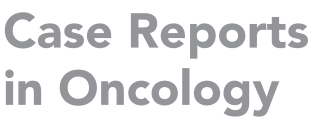

Case Reports in Oncology

\begin{tabular}{l|l}
\hline Case Rep Oncol 2020;13:1387-1392 \\
\hline DOI: 10.1159/000511112 & $\begin{array}{l}\text { @ 2020 The Author(s). Published by S. Karger AG, Basel } \\
\text { www.karger.com/cro }\end{array}$ \\
\hline
\end{tabular}

Muto et al.: EGFR-TKIs plus Bevacizumab for Combined LCNEC Harboring EGFR Mutation

\section{Introduction}

Tyrosine kinase inhibitors (TKIs) are now the first choice for treatment of non-small cell lung cancer (NSCLC) harboring epidermal growth factor receptor (EGFR) gene mutations. Recently, the efficacy of combination treatment of erlotinib with bevacizumab for NSCLC harboring EGFR mutations has been reported. Erlotinib and bevacizumab combination therapy improves progression-free survival to a greater extent than erlotinib monotherapy in patients with NSCLC harboring EGFR mutations [1, 2].

However, EGFR mutations have also been identified in large cell neuroendocrine carcinoma (LCNEC) of the lung [3-5]. LCNEC is a rare tumor of the lung, accounting for $3 \%$ of lung cancer cases, and is a type of neuroendocrine tumor. LCNEC resembles small cell lung cancer (SCLC) with features such as high-grade malignancy, poor prognosis, and high incidence in males and smokers. Both LCNEC and SCLC show neuroendocrine markers in immunohistochemistry. LCNEC is distinguished from SCLC by several morphological criteria including large cell size and abundant cytoplasm. Etoposide and platinum-based regimens are often selected for advanced LCNEC. LCNEC harboring EGFR mutations is extremely rare, and to our knowledge, only 2 cases of LCNEC treated with an EGFR-TKI have been reported to date, both of which were treated with gefitinib and showed a good response. Here we report a case of combined LCNEC with adenocarcinoma harboring an EGFR mutation treated with EGFR-TKIs and bevacizumab.

\section{Case Presentation}

A 70-year-old woman with no history of neoplastic disease presented with an abnormality identified by chest X-ray. Chest computed tomography (CT) scanning revealed a lung tumor in the left lower lobe. Tumor tissue obtained by transbronchial lung biopsy was diagnosed as LCNEC. Chromogranin A was positive in more than 50\% of the tumor, and CD56 was weakly positive (Fig. 1). Thyroid transcription factor 1 and cytokeratin 7 were positively expressed and cytokeratin 20 was partially positive. An activating EGFR mutation (exon 19, E746-A750 deletion) was detected by the PCR-INVADER method. Positron emission tomography scanning and brain magnetic resonance imaging (MRI) did not show distant metastasis. Surgical resection was performed. The patient's lung cancer had various histological
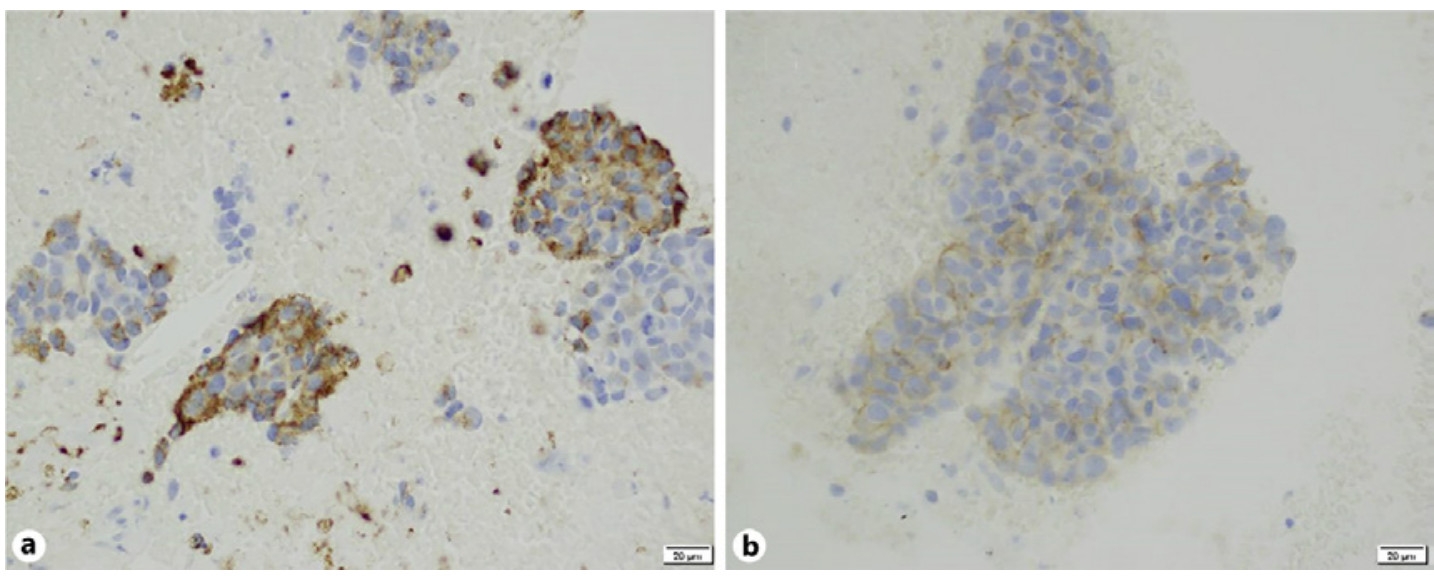

Fig. 1. Histological features. Chromogranin A was positive (a) and CD56 was weakly positive (b) in the tumor tissue obtained by transbronchial biopsy. 


\section{Case Reports in Oncology}

Case Rep Oncol 2020;13:1387-1392

DOI: $10.1159 / 000511112$

( 2020 The Author(s). Published by S. Karger AG, Basel www.karger.com/cro

Muto et al.: EGFR-TKIs plus Bevacizumab for Combined LCNEC Harboring EGFR Mutation
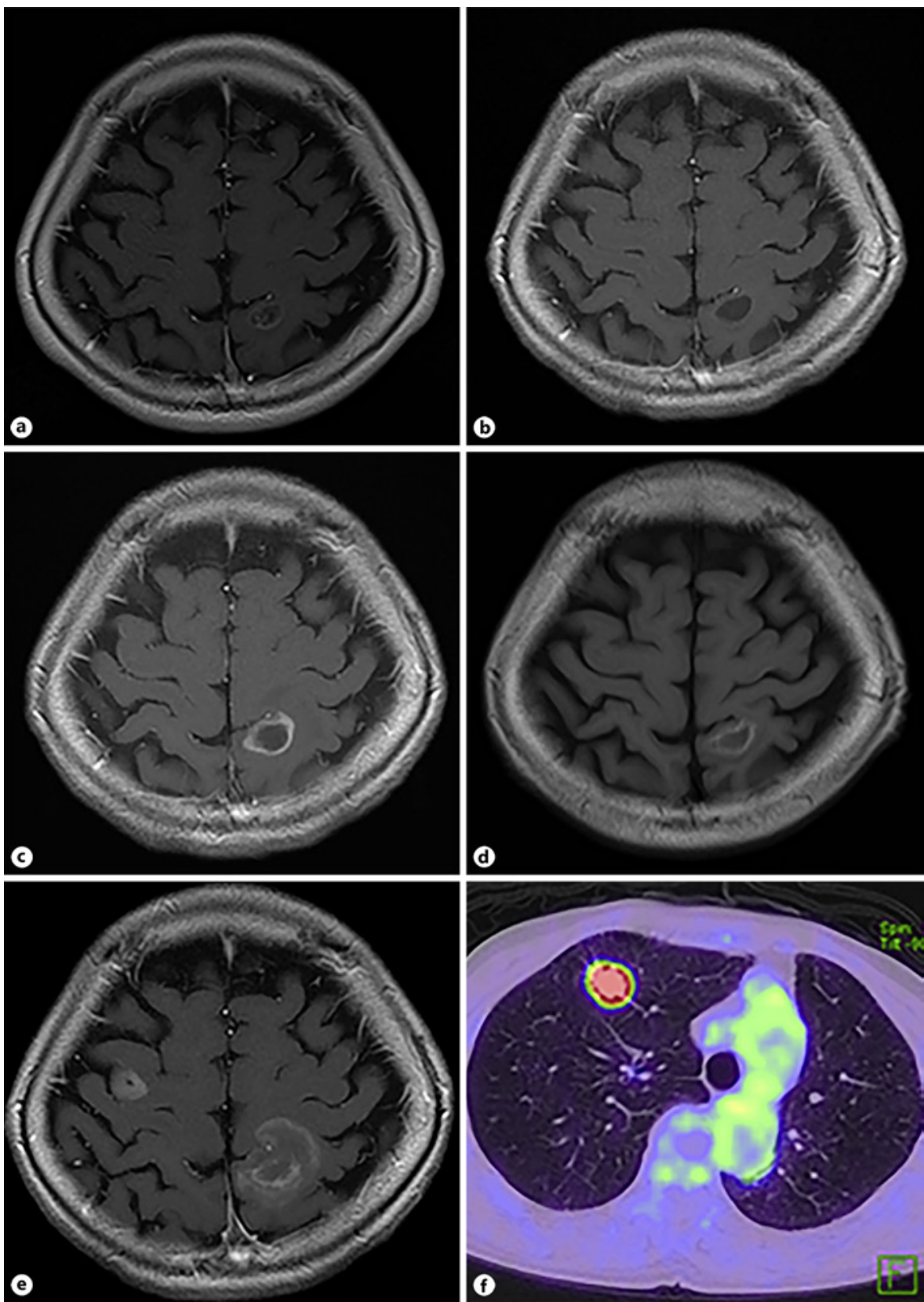

Fig. 2. Gadolinium-enhanced magnetic resonance imaging and positron emission tomography. Stereotactic irradiation followed by afatinib controlled brain metastasis (a) for 6 months (b). Ringed enhancement appeared 8 months later (c). Erlotinib and bevacizumab improved the perilesional edema, and stable disease was maintained for 6 months (d). Metastatic lesions in the brain (e) and lung (f) began to grow 10 months later.

features including rosette formation, necrotic tissue, and adenocarcinoma with an acinar and solid architecture. The pathological diagnosis was combined LCNEC with adenocarcinoma, and the pathological stage was T1cN1M0 stage IIB. Cisplatin and vinorelbine as adjuvant chemotherapy were administered only once after surgery because of several adverse events.

Eleven months later, the lung cancer recurred as a brain metastasis in her left parietal lobe (Fig. 2a) alongside a small lung metastasis. After stereotactic irradiation of this brain 
lesion, afatinib (20 mg/day) was administered as the first-line treatment, and stable disease was maintained for 6 months (Fig. 2b). The patient had grade 2 rash acneiform and paronychia during this period. Eight months later, paralysis of the right lower limb manifested. Brain MRI revealed ringed enhancement and perilesional edema after radiotherapy without new metastatic lesions (Fig. 2c). New lesions were not identified by positron emission tomography scan. The treatment was then switched to erlotinib $(150 \mathrm{mg} /$ day $)$ and bevacizumab (15 mg/kg q3w). The paralysis rapidly improved, and stable disease was maintained for 6 months (Fig. 2d). During this time, she had grade 2 paronychia, rash acneiform, anorexia, and hypertension. Erlotinib was decreased to $100 \mathrm{mg} /$ day at first, then $50 \mathrm{mg} /$ day. The lung metastatic lesion remained stable during the afatinib, erlotinib, and bevacizumab treatment period. After 10 months of treatment with erlotinib and bevacizumab, metastatic lesions in the brain and lung began to grow (Fig. 2e, f). EGFR ${ }^{\mathrm{T} 790 \mathrm{M}}$ mutation was not found in serum biopsy.

\section{Discussion}

LCNEC of the lung is a rare tumor, and there are no established standard treatment strategies. Cases of advanced or recurrent LCNEC are often treated as SCLC [6]. It was reported that LCNECs have a similar genomic profile to SCLC, including TP53 mutations and genetic alterations in the PI3K/AKT/mTOR pathway, and EGFR mutation was detected in only one of 78 LCNEC samples [7]. There are few reports that describe EGFR-TKI treatment of EGFRmutated LCNECs $[4,8]$. Gefitinib was selected in both of these previous reports and resulted in a good response. In our case, we first conducted radiotherapy because of brain metastasis and subsequently administered afatinib. After progression of the disease, we undertook treatment with erlotinib and bevacizumab because of brain edema around the metastatic lesions.

Vascular endothelial growth factor produced in the perinecrotic area is thought to be a major cause of both angiogenesis and perilesional edema after radiation therapy to metastatic lesions of the brain [9]. The efficacy and safety of bevacizumab treatment for brain metastasis of NSCLC are well known [10-12], while efficacy of bevacizumab combined with EGFR-TKIs for EGFR-mutated NSCLC with brain metastasis has also been reported $[13,14]$. Furthermore, Mairinger et al. [15] reported that angiogenesis was also activated to some extent in LCNECs. Thus, the addition of bevacizumab to treatment regimens for LCNECs is thought be one of the reasons for the long-term effectiveness of this treatment strategy.

A limitation of our study is that we could not perform biopsies of the recurrent lesions. Because our patient had combined LCNEC with adenocarcinoma, recurrent lesions might have consisted of adenocarcinoma components. Despite this limitation, this is the first report showing the activity of EGFR-TKIs and bevacizumab in LCNEC harboring an EGFR mutation. EGFR-TKIs and bevacizumab could be a treatment option for LCNECs harboring EGFR mutations, especially with brain metastasis.

\section{Acknowledgements}

We thank H. Nikki March, PhD, from Edanz Group (www.edanzediting.com/ac) for editing a draft of this manuscript.

\section{Karger's}




\section{Case Reports in Oncology}

\begin{tabular}{l|l}
\hline Case Rep Oncol 2020;13:1387-1392 \\
\hline DOI: 10.1159/000511112 & $\begin{array}{l}\text { ○ 2020 The Author(s). Published by S. Karger AG, Basel } \\
\text { www.karger.com/cro }\end{array}$ \\
\hline
\end{tabular}

Muto et al.: EGFR-TKIs plus Bevacizumab for Combined LCNEC Harboring EGFR Mutation

\section{Statement of Ethics}

Written informed consent was obtained from the patient for the publication of this case report.

\section{Conflict of Interest Statement}

The authors have no conflicts of interest to declare.

\section{Funding Sources}

The authors have no funding sources in regard to this case report.

\section{Author Contributions}

Conceptualization: Satoshi Muto and Hiroyuki Suzuki. Investigation: Satoshi Muto. Resources: Yuki Ozaki, Naoyuki Okabe, Yuki Matsumura, Takeo Hasegawa, and Yutaka Shio. Supervision: Hiroyuki Suzuki. Validation: Yuko Hashimoto. Writing - original draft: Satoshi Muto. Writing - review and editing: Satoshi Muto and Hiroyuki Suzuki.

\section{References}

1 Seto T, Kato T, Nishio M, Goto K, Atagi S, Hosomi Y, et al. Erlotinib alone or with bevacizumab as first-line therapy in patients with advanced non-squamous non-small-cell lung cancer harbouring EGFR mutations (J025567): an open-label, randomised, multicentre, phase 2 study. Lancet Oncol. 2014 Oct;15(11):1236-44.

2 Saito H, Fukuhara T, Furuya N, Watanabe K, Sugawara S, Iwasawa S, et al. Erlotinib plus bevacizumab versus erlotinib alone in patients with EGFR-positive advanced non-squamous non-small-cell lung cancer (NEJ026): interim analysis of an open-label, randomised, multicentre, phase 3 trial. Lancet Oncol. 2019 May;20(5):62535.

3 Iyoda A, Travis WD, Sarkaria IS, Jiang SX, Amano H, Sato Y, et al. Expression profiling and identification of potential molecular targets for therapy in pulmonary large-cell neuroendocrine carcinoma. Exp Ther Med. 2011 Nov-Dec;2(6):1041-5.

4 De Pas TM, Giovannini M, Manzotti M, Trifirò G, Toffalorio F, Catania C, et al. Large-cell neuroendocrine carcinoma of the lung harboring EGFR mutation and responding to gefitinib. J Clin Oncol. 2011 Dec;29(34): e819-22.

5 Sakai Y, Yamasaki T, Kusakabe Y, Kasai D, Kotani Y, Nishimura Y, et al. Large-cell neuroendocrine carcinoma of lung with epidermal growth factor receptor (EGFR) gene mutation and co-expression of adenocarcinoma markers: a case report and review of the literature. Multidiscip Respir Med. 2013 Jul;8(1):47.

6 Fasano M, Della Corte CM, Papaccio F, Ciardiello F, Morgillo F. Pulmonary large-cell neuroendocrine carcinoma: from epidemiology to therapy. J Thorac Oncol. 2015 Aug;10(8):1133-41.

7 Miyoshi T, Umemura S, Matsumura Y, Mimaki S, Tada S, Makinoshima H, et al. Genomic profiling of large-cell neuroendocrine carcinoma of the lung. Clin Cancer Res. 2017 Feb;23(3):757-65.

8 Aroldi F, Bertocchi P, Meriggi F, Abeni C, Ogliosi C, Rota L, et al. Tyrosine kinase inhibitors in EGFR-mutated large-cell neuroendocrine carcinoma of the lung? A case report. Case Rep Oncol. 2014 Mar;7(2):478-83.

9 Nonoguchi N, Miyatake S, Fukumoto M, Furuse M, Hiramatsu R, Kawabata S, et al. The distribution of vascular endothelial growth factor-producing cells in clinical radiation necrosis of the brain: pathological consideration of their potential roles. J Neurooncol. 2011 Jun;105(2):423-31.

10 Socinski MA, Langer CJ, Huang JE, Kolb MM, Compton P, Wang L, et al. Safety of bevacizumab in patients with non-small-cell lung cancer and brain metastases. J Clin Oncol. 2009 Nov;27(31):5255-61.

11 De Braganca KC, Janjigian YY, Azzoli CG, Kris MG, Pietanza MC, Nolan CP, et al. Efficacy and safety of bevacizumab in active brain metastases from non-small cell lung cancer. J Neurooncol. 2010 Dec;100(3):443-7.

12 Besse B, Le Moulec S, Mazières J, Senellart H, Barlesi F, Chouaid C, et al. Bevacizumab in patients with nonsquamous non-small cell lung cancer and asymptomatic, untreated brain metastases (BRAIN): a nonrandomized, phase II study. Clin Cancer Res. 2015 Apr;21(8):1896-903. 
13 Chikaishi Y, Kanayama M, Taira A, Nabe Y, Shinohara S, Kuwata T, et al. Effect of erlotinib plus bevacizumab on brain metastases in patients with non-small cell lung cancer. Ann Transl Med. 2018 0ct;6(20):401.

14 Jiang T, Zhang Y, Li X, Zhao C, Chen X, Su C, et al. EGFR-TKIs plus bevacizumab demonstrated survival benefit than EGFR-TKIs alone in patients with EGFR-mutant NSCLC and multiple brain metastases. Eur J Cancer. 2019 Nov;121:98-108.

15 Mairinger FD, Walter RF, Werner R, Christoph DC, Ting S, Vollbrecht C, et al. Activation of angiogenesis differs strongly between pulmonary carcinoids and neuroendocrine carinomas and is crucial for carcinoid tumourgenesis. J Cancer. 2014 May;5(6):465-71. 